\title{
EL ENSAYO DESDE LAS HUMANIDADES DIGITALES: EL ENSAYISMO ERRANTE COMO HIPERENSAYO.
}

\author{
Vicente Luis Mora \\ (Universidad de Málaga)
}

\begin{abstract}
me atrevo a afirmar que un ensayo, o aun varios ensayos combinados, no prueban nada, e incluso que no hay cosa más peligrosa que querer demostrar un corolario inmediatamente por ensayos.J. W. Goethe (2000: 47)

Es importante tener presente que en Internet somos nosotros con tecnología. Scott Esposito (2016: 119)
\end{abstract}

En teoría, una de las mejores formas de demostrar las posibilidades del ensayo digital es la escritura de un ejemplo, sea o no paradigmático, poniendo a prueba sus posibilidades expresivas (incluso digresivas) al construir la reflexión sobre el ensayo digital como hipertexto, es decir, como hiperensayo. Objeto y método coincidirían, en tal caso, demostrando mediante la práctica la polivalencia del género y su capacidad de mutación formal y discursiva, amén de utilizar los recursos (hipervinculación, minería de textos) que recomienda la metodología de las Humanidades Digitales (López Poza, 2014: 153; Spence, 2014: 9; Pons, 2013: 33ss). En lo que sigue vamos a intentarlo.

\section{Estado de la cuestión.}

Si el ensayo, como decía Bárbara Jacobs, es «una forma de expresión escrita en prosa y en primera persona del singular (...) con cohesión pero sin una meta predeterminada» (2008:27), habría que concluir que, o bien el género ha desaparecido en las tecnologías comunicativas surgidas durante los últimos decenios, o bien, como intentaremos demostrar, el género ha mutado. El ensayo hoy ni tiene lugar sólo en prosa (los hay en cómic, por ejemplo La rue del 
Percebe de la cultura y la niebla de la cultura digital, 2015, de Mery Cuesta, o Unflattening, 2015, de Nick Sousanis; también hay video-digresión de calidad vía YouTube), ni sólo en primera persona; tampoco busca siempre la cohesión y no es ya tampoco invariablemente la libre divagación sobre cualquier tema sin buscar demostración, como desde antaño se venía entendiendo. Pedro Aullón de Haro proponía con sensatez, hace ya veinticinco años, hablar de «géneros ensayísticos» (1992: 103), ensanchando el término «ensayo», para manifestar la heterogeneidad y diversidad ínsitas al término, utilizado por igual para catalogar monografías académicas que libros divulgativos o ensayos literarios à la Montaigne. Basta ver la lista de libros premiados con el Nacional de Ensayo (cf. Pozuelo Yvancos, 2005), para dar idea de la polisemia con que se acoge un «género» capaz de aglutinar libros tan diversos.

A esa apertura o heterogeneidad nos acogeremos a la hora de entender cuáles puedan ser las líneas de fuga del ensayo en el mundo digital, aunque algunas características tradicionales del término vienen permitiendo desde tiempo atrás una interpretación amplia y polifacética del ensayo en nuestros días. Adorno explicó muy bien en su momento que el ensayo debe sacudirse el método inductivo, herencia del cartesianismo, y partir de lo complejo y no de lo simple: «el ensayo se sacude la ilusión de un mundo sencillo», porque «su carácter diferenciador no es un añadido, sino su medio» (2003: 25). Por su relación natural con la complejidad, es un instrumento discursivo perfecto para entender realidades especialmente complejas, como la sociedad-red actual (Castells, 2001), y fluir por canales de comunicación estructuralmente complejos, como Internet (Mora 2006: 224ss). El ensayo digital responde a la perfección a otro desiderátum adorniano: «a su forma le es inmanente su propia relativización: tiene que estructurarse como si pudiera interrumpirse en cualquier momento", algo inherente a las redes sociales, porque "piensa en fragmentos lo mismo que la realidad es fragmentaria, y encuentra su unidad a través de los fragmentos, no pegándolos» (Adorno 2003: 26). Esta complejidad pangeica es hoy aceptada «sistémicamente» por las teorías comunicativas y sociológicas, que desde las teorías de los riesgos conectados (Ulrich Beck, 1992) a la ecología de medios (Scolari, 2015) se hacen cargo de la dificultad de entender o leer de un vistazo nuestro mundo. Esas mismas teorías, como ahora veremos, recogen otro elemento característico de los nuevos medios digitales: el fundamental papel central de la subjetividad. 


\section{Ensayo y subjetividad digital.}

Cada ensayo que leemos representa lo más cerca que podemos acercarnos a otra mente. Es una simulación de la mente que se ocupa de un problema.

Ander Monson (2011)

El ensayo es uno de los géneros literarios en cuya descripción se hace más hincapié en valores subjetivos. Comentando el caso de Montaigne, escribe Jean Starobinsky: «Éste es el aspecto reflexivo, la vertiente subjetiva del ensayo, en el cual la consciencia de sí se despierta como una nueva instancia del individuo, instancia que juzga la actividad del juicio, que observa la capacidad del observador» (1998: 36); según leyes antiguas el ensayista, antes que nada, «debe ensayarse a sí mismo» (Starobinsky, ibídem). Muchas de las definiciones clásicas sugieren o develan explícitamente el temperamento de la persona que está tras el ensayista, «emanando» su personalidad en una codificación histórica y literariamente determinada. Observemos esta descripción de Arturo Souto: «el ensayo es un escrito, por lo común breve, sobre temas muy diversos. No lo define el objeto sobre el cual se escribe sino la actitud del escritor ante el mismo», añadiendo que es una "actitud de prueba, de examen, a veces de tentativa o de sondeo» (1973: 8). Así pues, encontramos una serie de rasgos que relativizan la objetividad del género, que eliminan el rigor científico de su horizonte de expectativas y que lo enmarcan en una actitud escrituraria de la persona que pretende ensayar, tentar, probar. Una actitud muy en la línea, permítasenos decirlo, del internauta contemporáneo, de aquella persona que se asoma a Internet para emitir su opinión por escrito. Ismael Gavilán habla de perspectiva: «todo escribir ensayístico aspira a una 'perspectiva', porque el yo que se despliega en la escritura busca o tantea un equilibrio ante el vértigo y el abismo de su discurrir» (2010: 76). La psicología del internauta, volandera y curiosa, desparramada pero siempre atenta, nos recuerda a la del Ulrich de El hombre sin atributos, naturalmente inclinada, como expresaba con agudeza Musil, al «ensayismo» no cómo práctica, sino como forma de ser:

Él no era filósofo. Los filósofos son opresores sin ejército (...) Esto influía en su conducta, de manera que todo lo que veía le inducía a reflexionar, a pesar de la prevención que tenía a pensar demasiado. Pero lo que en definitiva decidía su comportamiento era otra cosa muy distinta. Había algo en el ser de Ulrich que obraba de un modo distraído, paralizante, desarmador, contra el orden 
lógico, contra la voluntad inequívoca, contra los impulsos de la ambición concretamente dirigidos, y también esto estaba comprendido con el nombre por él elegido de 'ensayismo' (2002: 260)

Ulrich, como buen conocedor del método científico, relaciona el término ensayo con su empleo a la hora de dirimir aquel método como ensayo más error, añadiendo que para él el ensayo no es sólo la expresión de una certidumbre personal, sino también un error (Musil 2002: 261) casi constitutivo. El ensayo, entendido en estas laxas condiciones, no es tanto la expresión de un pensamiento concreto como la expresión de un pensamiento, del modo mismo de pensar. Y si aceptamos, con Broncano (2012: 90-93) y Escandell que la escritura supone una transformación del lenguaje de la representación, y que esta metanoia implica «una reconfiguración del pensamiento a través de la expresión lingüística escrita que va también más allá de una visión instrumentalizada de la cultura material» (Escandell 2014: 76), nos damos cuenta de hasta qué punto están relacionadas una escritura diferente y un pensamiento diferente. De hecho, el propio Fernando Broncano vive entre ambos mundos, ajustando su pensamiento al laberinto de la identidad de su escritura. Si el ensayo, como vindica Pozuelo Yvancos, es el género que ejecuta la «Tensión del yo con el evento, acontecimiento, asunto o situación» (2005: 188), parece especialmente adecuada la forma agresiva y directa de las redes sociales para confrontar las situaciones de presente y responder a su desafío discursivo con una toma de postura inmediata, hipersubjetiva (como lo es gran parte del discurso digital, según Sherry Turkle, 1997 y Eva Illouz, 2007) y mutable, flexibilizada por su condición de palimpsesto. Internet es el lugar natural del ensaYo, en el seno de una sociedad tan acostumbrada al yo que comienza a dar avisos de cansancio (Caballé, 2017). Esto, paradójicamente, no quiere decir que la expresión sea egocéntrica, puesto que la red es también el lugar natural de la desaparición subjetiva, gracias a su capacidad para el anonimato y el pseudónimo. Hay blogs muy interesantes de los que sólo sabemos el mote, nom de plume o seudónimo de su administrador, sin asidero de nombres o fotos reales. En esos supuestos también se diluye otra característica aneja al ensayo tradicional, su responsabilidad, el hecho de ser la opinión sostenida por un yo inequívoco. En un libro que en sí mismo es una pregunta sobre los límites entre los géneros, Perros en la playa, Jordi Doce recuerda cómo frente a la irresponsabilidad del autor de novelas, el ensayo hace responsable al ensayista: 


\begin{abstract}
El ensayo, el aforismo o la reflexión moral son géneros breves no sólo por la presunta agudeza (cierta agilidad imprevisible) del pensamiento fragmentario y asistemático. La pretensión tácita de lectores y críticos es que su autor respalde sin ambages todo lo dicho, lo apuntado, lo sugerido: no con argumentos más o menos trabados sino con su ejemplo. Se trata de una condición que parece asegurar, para muchos, la veracidad de lo escrito. Pero es también una petición de responsabilidad que abruma al escritor y le sugiere la conveniencia de callar más largamente de lo que quisiera.
\end{abstract}

Durante mucho tiempo, algunos blogs o cuentas de Twitter que procuraban mediante pseudónimo a sus lectores notables reflexiones, pienso en el blog literario El lamento de Portnoy o en la cuenta de Twitter @ NeinQuarterly, actuaron sin nombre, pero eran influyentes y tenían centenares o miles de seguidores. Esos perfiles tenían firma ensayística, pero no responsabilidad. Hoy sabemos que tras el primero estaba el escritor Javier Avilés y tras la segunda el filósofo Eric Jarosinski, que luego reunió parte de sus tuits filosóficos en el ensayo Nein. A Manifesto (2015), pero durante bastantes años lo importante de esas reflexiones en línea no era su autoría, sino su talentoso e inteligente contenido, que actuaba como subjetividad sin sujeto responsable.

\title{
El ensayo enmarcado dentro de la nueva textualidad.
}

Una de las características clásicas del ensayo, apuntada por Lukács (1985: 13-15), era la de su condición inacabada, sin voluntad de cierre categorial ni de terminación de una discusión o asunto concreto. Es otro punto en común que tiene en común con los textos digitales de hogaño, planteados más como preguntas que como respuestas definitivas a las cuestiones. A ello anima la especial naturaleza del texto en el mundo digital, que hemos definido como «internexto» (2013) y a la que otros se han referido como «cibertext» (Aarseth, 1997) o «fluid textuality» (Katheleen Komar en Simanowski 2016: 257). Esto afecta a la pragmática del ensayo, y debe tenerse en cuenta que «algunos géneros (v. gr. Poemas) presentan una codificación más estricta en el nivel fonológico y sintáctico, mientras que otros (recetas, leyes) ponen más énfasis en la semántica y la pragmática» (Ryan 261); entiendo que el ensayo pertenece más bien a este segundo grupo, y por lo tanto debemos rastrear el modo de aparición de sus manifestaciones escritas digitales, ahondando sobre su textualidad con el apoyo metodológico de las Humanidades Digitales, 
según apuntábamos al comienzo. Como hemos señalado más arriba, a partir de Broncano y Escandell, esta textualidad está directamente imbricada en el pensamiento del que trae causa, como temperamento o perspectiva textual. Por ese motivo, «el yo ensayístico -desplegado en la máxima, el aforismo, la anotación- no busca la textualidad concebida como los restos de una totalidad perdida que hay que salir a recobrar» (Gavilán 2010: 80), enmarcado en la técnica dispositiva que llamamos en otro lugar «fragmentarismo» (Mora 2015) o discontinuidad, frente al «fragmentalismo» o continuidad en mosaico de corte moderno, nostálgico este último con respecto a la existencia de una unidad unificadora de todas las piezas. Otro elemento a tener en cuenta, para aprehender la complejidad del fenómeno, es la interactividad de los internautas y la condición de palimpsesto del texto digital, por lo que una descripción de su fenomenología podría ser ésta de Anxo Abuín, enmarcada dentro de un espectro más amplio, el digimodernismo, que el autor extiende también a algunas realidades analógicas:

\footnotetext{
Entramos también en la era del «digimodernismo», una especie de postmodernismo tamizado por la omnipresencia de lo digital. El texto digimodernista se caracterizaría precisamente por la dependencia absoluta del lector ya no para ser interpretado, sino para configurarse físicamente como tal, pues se presenta en forma evanescente, blanda o flexible. Sus rasgos son la creación colectiva, la performatividad, pues se presenta como incompleto y en crecimiento (onwardness); una sensación de azar o imprevisibilidad en el desarrollo de las líneas de trama (haphazardness); la reformulación de los roles textuales, que no excluye la experiencia con las redes sociales; la fluidez de unos textos que se expanden sin límites. No todas valen en la misma medida para los casos analizados, que, sin embargo, se presentan, a través del uso inteligente de las nuevas tecnologías, como textos que celebran la participación, la narratividad abierta y la complejidad como valores de la realidad discursiva que nos espera en el futuro. (Abuín 2013: 245)
}

En consecuencia, las tecnologías aparecidas desde 1993, fecha de creación de la World Wide Web, han creado todo un conjunto de posibilidades para delimitar los márgenes de una pragmática del pensamiento escrito digital. De entre todas ellas cobra especial relevancia el blog o bitácora (cf. Mora, 2006), por estar estructuralmente configurado para la escritura libre y subjetiva en línea, dejando plena capacidad al usuario para elegir el tema, la forma, la extensión, la apariencia, y la posibilidad de integrar imágenes, hipervínculos a otros textos, vídeos, etcétera. «El blog podría ser una zona liberada para el ensayo», escribe la editora y narradora mexicana 
Vivian Abenshushan, "una zona apartada de toda utilidad, ajena a los intereses de la industria o la nueva escolástica y por eso abierta a la experimentación más radical» (2012: 12). A su juicio, su forma es casi naturalmente hospitalaria para el pensamiento digresivo: «En la prosa fragmentaria que el blog propicia el ensayista podría practicar la insumisión del lenguaje sin temor a los editores y, sobre todo, la exploración paciente y cotidiana de una idea personal, arriesgada, incómoda» (Ibíd.), añadiendo algo de interés para nosotros: «además, la red parece una zona más propicia para la digresión que la página, y en su forma de saltos y links ha dotado al ensayo, a posteriori, de su ambiente natural» (Abenshushan, 2012: 12-13). La posibilidad de vínculos es importante para definir la singularidad del texto digital, convertido gracias a ellos en intertexto, aunque sólo si la posibilidad se utiliza bien será un potenciador teórico: «el hipertexto se convierte en un objeto comunicativo más abierto, interactivo y versátil sólo si el usuario es capaz de potenciar esas habilidades en procesos cognitivos complejos» (Fernández Massara, 2014: 131). El bloguero, por tanto, es un escritor que funciona como una máquina de producir sentido, gracias a un soporte digital cuya función es continuar la función digresiva y seguir pensando ensayísticamente. Su labor no es productora en un sentido mercantil, pues su quehacer es gratuito y desprendido, sino generador, interminable, productivo en el sentido de feraz: en principio, un blog no tiene fin. Puede seguir y seguir construyéndose de forma indefinida. Comentando las aportaciones de Morot-Sir y Bensmaïa, Carles Besa Camprubí apunta algo que nos resulta de mucho interés para entender la actividad del bloguero y la del microensayista de las redes sociales: «El ensayo no razona 'per articulatio' sino 'per acumulatio'» (2014: 113), agregando sentido al sentido o sinsentido ya existente.

\section{La red como «canal» del ensayo.}

Las tecnologías digitales han provocado la puntual desaparición de muchos mediadores, entre ellos los editoriales. Aunque creamos -y, aunque depende del día, yo suelo creerlo- que un buen editor garantiza profesionalmente la mejora del texto, el hecho es que para publicar algo -no así para editar-, ya no es necesario un editor. Según Boris Groys, «el surgimiento de Internet eliminó esta diferencia entre producción y exhibición del arte» (2016: 203). Para algunos esto es algo parecido al apocalipsis intelectual, pero la práctica diaria nos enseña otra cosa. Quienes han pasado ya muchas veces por el filtro de un editor pueden hacer publicaciones 
sólidas y de calidad sin él, precisamente porque han asumido el procedimiento para mejorar sus textos, tras incontables horas de revisión de galeradas y conversación con editores. Y ello ha permitido que abunde el ensayo de interés en Internet. Ya hemos citado el caso del filósofo Jarosinski, pero hay más: Steven Shaviro, Katherine Hayles, Ander Monson, Remedios Zafra, Mark Amerika, los colaboradores de infinitas páginas de pensamiento, filosofía y ensayo que sólo escriben en línea... Otro caso sería el del filósofo José Luis Molinuevo, quien, tras haber publicado en editoriales prestigiosas, en los últimos años ofrece en su blog para descarga gratis su serie ensayística "Archipiélagos", que suele abordar temas referentes al pensamiento en imágenes. Gracias también al formato blog, por ejemplo, gran parte del pensamiento literario hispanoamericano se está haciendo directamente en Internet, a veces sin traslación al papel; nombres como Cristina Rivera Garza, Rafael Lemus, lorge Téllez, Christopher Domínguez

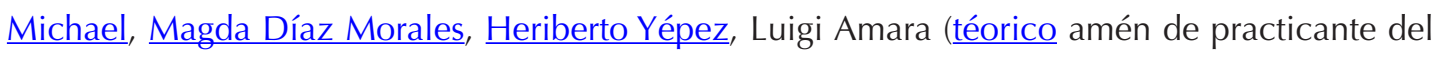
ensayo), Belén Gache o Laura Borràs elaboran o comparten digitalmente sus reflexiones, que luego pueden acabar publicadas en papel, aunque lo normal es que esto no suceda. Gustavo Guerrero ha recordado que «varios trabajos universitarios que han trabajado recientemente en el tema», entre los que cita los de Stefano Tedeschi y Mario Martín Gijón, aunque pueden agregarse otros de su propia cosecha, «han puesto de relieve justamente esta interactividad, amplitud y plasticidad del blog que lo convierten en un soporte idóneo para la ensayística actual» (2014: 68). El lector de ensayo literario actual debe tener la costumbre de ir leyendo y anotando sus textos, a veces salvándolos a archivos Word o PDF, para conservarlos y poder citarlos en trabajos posteriores. Páginas web de suplementos literarios como el New York Times o Los Angeles Times han alojado (no así sus homólogos en papel) vivos debates sobre el presente y el futuro de la crítica literaria, con ensayos largos y sesudos, que ya no tienen cabida en la versión impresa del mismo medio. De forma paradójica, da la impresión de que cierto ensayo de actualidad, precisamente por su profundidad y extensión, carece de otro espacio que no sea la red.

Además de su condición de soporte formal, que para algunos es además una forma de resistencia política ante el mercado literario, podríamos hacer referencia a la red como canal de distribución o difusión del ensayo. Gracias a la red es posible plantear algunas colecciones de ensayo directamente para la circulación digital, como las del Centro de Cultura Digital de México, en colaboración con Publicaciones Malaletra Internacional, o que conviven con la 
edición en papel, a veces difundiéndose de forma gratuita en línea, como las colecciones de ensayo de La Tumbona Ediciones, o el catálogo de Acuarela. Por no hablar de otras formas de difusión del ensayo a través de Internet que no son legales, pero que son muy utilizadas, y que están en la mente de todos.

\section{¿Contienen las redes sociales ensayo aforístico?}

El poeta y ensayista Eduardo García, tempranamente desaparecido el pasado año, dejó escrito que «el ensayo es un grandilocuente espejo deformado. El libro de aforismos, un álbum de instantáneas donde queda la estela de esa muchedumbre a la que llamamos yo» (2014: 65). El aforismo tiene un carácter singular, a medio camino entre el ensayo, la poesía, el fragmento, el dietario y el apunte de diario íntimo, tomando un poco de todos, según casos y prácticas. Con aforismos se puede hacer filosofía (Nietzsche, Adorno), microensayo (Antonio Porchia, Ramón Andrés, Jorge Wagensberg), preceptiva literaria (Piglia, Bolaño, Neuman), preceptiva moral (Gracián, La Rochefoucauld, Joubert), sátira (Lec, Kraus), poesía (Wallace Stevens, Lorenzo Oliván), literatura no convencional (Cristóbal Serra, Azahara Alonso) y lo que se quiera, salvo -quizá- novela. José Ángel Valente decía que «En el aforismo confluyen poesía y pensamiento» (2000: 114), y Julián Serna Arango que «El aforismo es más que un ensayo bonsái» (2006: 51). No es casual que el fragmento sea parte esencial de la Weltschauung de nuestro tiempo; como ha explicado José Jiménez,

Es el tiempo de la pluralidad, de lo discontinuo, de la dispersión, del fragmento. El pensamiento, las creencias religiosas, las artes en su conjunto, las propias formas de vida, muestran bien a las claras tales características. (...) ensayo y fragmento (...) son formas expresivas características de la modernidad: pero, además, el ensayo está impregnado de fragmentariedad, frente al género totalizante del «tratado», respecto al cual constituye una alternativa. Fragmento y ensayo son, en último término, dos consecuencias de un mismo proceso de disolución de los discursos homogeneizadores y totalizantes. Ambos se implican mutuamente en el plano de las posibilidades expresivas abiertas en la modernidad. Las reservas contra el fragmento nacen de la sospecha de que en él pudiera latir la nostalgia de la totalidad. pero, en lugar de ello, es posible reivindicar el fragmento como singularidad de una puesta en común no totalizante y, sobre todo, como límite o reserva de la memoria de nuestra civilización. (1989: 21) 
La red tiene esas dos dimensiones, es pensamiento + archivo. El activo cultural de nuestro espacio-tiempo tiene su doble o réplica digital en el ciberespacio, caracterizado por una estructura rizomática carente de centro. Esto quiebra la concepción clásica del ensayo: «Un libro, incluso un libro fragmentario, tiene un centro que lo atrae», apuntaba Blanchot en las palabras de apertura de El espacio literario, continuando de este modo: «El que escribe el libro, lo escribe por deseo, por ignorancia de ese centro (...) cuando se trata de un libro de ensayos, hay una cierta lealtad metódica en aclarar hacia qué punto parece dirigirse el libro» (1992: 4). El ensayo en línea, fragmentarista o discontinuo pero no fragmentalista (Mora, 2015), no dirige su pulsión discursiva hacia un centro en concreto, sino que la dispersa por doquier, hacia todas partes al mismo tiempo. Es simultáneo, y, como escribía José-Carlos Mainer en Libros, tramas, nombres, «un ensayo (...) comporta la simultaneidad del discurso teórico principal y el desarrollo, quizá en clave menor, de la razón por la que se escribe» (2005: 117). La condición fractal y viajera del internexto permiten a la escritura ensayística desatarse por los campos luminosos de los signos, porque «el ensayismo no oculta su dimensión errante» (Jarauta 1999: 57).

Una de sus mutaciones puede ser la aparición de las redes sociales de microblogging, en particular Facebook y Twitter. Mientras que Facebook ya permite, desde hace años, textos de extensión indeterminada, con lo cual la cuestión en esa red no tiene demasiadas particularidades frente al blog, el caso de Twitter es más complejo. La limitación de los tuits a 140 caracteres delimita un límite metafísico de lenguaje que suele oponerse a la creación de cualquier discurso intelectual de fuste. Sin embargo, reiteradas opiniones se han mostrado en contra. En un reciente ensayo, Paulo A. Gatica Cote recoge posturas de todo tipo al respecto, incluye un debate que tuvo lugar en Twitter entre los tuiteros y escritores Aurelio Asiain, $\underline{\text { Hilda Acevedo y Mael Aglaia }}$ al respecto (2016: 265), y cita diversos argumentos que intentan conectar y separar el aforismo del tuit. En sus conclusiones apunta que «la escritura aforística y ensayística adquiere en las redes sociales un nuevo marco intersubjetivo de producción y recepción, donde se advierte con claridad cómo la llegada del universo digital ha modificado las nociones de literatura y género literario» (Gatica Cote, 2016: 267), algo con lo que estamos de acuerdo, ya que en 2015 dejamos claro que «la creación literaria en las redes sociales podría ser considerada literatura, aunque solo sea porque los problemas de validez y legitimación que genera son los mismos que los de la literatura tradicional» (2012), idea en la que hemos insistido en otro trabajo reciente sobre 
tuiteratura (2016). Hay una cuenta en Twitter que publica constantemente aforismos y greguerías de Ramón Gómez de la Serna; las diferencias podrán ser pragmáticas y de dispositio, pero no de elocutio, ni afectan a la integridad ni a la calidad del texto. Son el mismo talento por otros medios, ergo son literatura; y si aceptamos que hay ensayo aforístico o aforismos-ensayo, no cabe más remedio que concluir que es posible hacer ensayo incluso a través de Twitter; tanto más cuanto los hashtags o etiquetas con que Twitter permite enlazar varios tuits dan la posibilidad al ensayista de hacer ensayos hilados, compuestos por decenas o centenares de tuits enlazados por hipervínculos, como ahora veremos.

\section{Algunos «hiperensayismos».}

Citaremos a continuación algunos ejemplos de ensayismo actual que utilizan las posibilidades tecnológicas, configurando «Un tejido relator (...) que deviene pliegue» (Buj 2016: 150); en alguno de los casos, en realidad, los ensayos no serían pensables sin esas características. Una de ellas podría ser la del poeta, profesor y ensayista Ander Monson, ya citado, que en su página web acoge brillantes reflexiones ensayísticas, Ilenas de autoironía, inteligencia y sentido del humor; si Alberto Giordano distinguía entre un ensayo tradicional, que busca la comunicación, y otro que se columbra como una «experiencia irónica de los límites de lo comunicable» (2015: 16), el ensayo digital de Monson pertenece al último tipo. Daniel Escandell ha estudiado otros ejemplos, por ejemplo el de Our Choice (2011), el ensayo de Al Gore, vertebrado como «un libro expandido repleto de vídeos, explicaciones adicionales en audio, mapas interactivos y otros contenidos interactivos que se vende también como libro impreso y como audiolibro» (Escandell 2014: 79), que aprovecha las posibilidades hipermedia para redefinir su mensaje y también sus posibles destinatarios. El mismo autor señala otro posible ejemplo, el del profesor Antonio Rodríguez de las Heras, un estudioso y a la vez practicante inquieto de las tecnologías:

\footnotetext{
Más significativo puede resultar el caso de Los estilitas de la sociedad tecnológica (2001), hiperensayo explorativo diseñado sobre el software Shockwave que publicó Antonio Rodríguez de las Heras en 2001, donde el receptor debe aprender a usar/navegar por el ensayo e interactuar expresamente para poder desplazarse en la estructura rizomática que compone, por tanto, una lectura no lineal y activa por parte de los receptores. Se trata de un ensayo diseñado y concebido para un sistema alejado ya plenamente de la estructura secuenciada del papel —real y electrónico—. (Escandell 2014: 80)
} 
Como vemos, se vuelve al entrecruzamiento entre la voluntad discursiva del ensayista o ciberensayista y el medio que elige o más bien diseña para expresarse. Para definir las posibilidades discursivas de la escritura digital, Cruz Arzábal apunta que una posible estrategia sería utilizar la terminología de dispositivo, desarrollada por Agamben, Deleuze o Holmes:

\footnotetext{
Así, un libro, una puesta en escena, una instalación electrónica, una pieza de arte electrónico, etc., pueden funcionar como dispositivos que ponen en relación a los seres con un conjunto de relaciones; no importará si éstos se presentan bajo la forma de un objeto relativamente estable o si existen en formas múltiples y simultáneas; lo central, para el caso, es que se trate de conjuntos de elementos que hagan visibles los modos en los que se generan subjetividades o que desvíen las subjetividades creadas por otros dispositivos (2014)
}

Y esta categoría podría aplicarse sin problemas a Jesús Martín-Barbero, uno de los ensayistas hispanoamericanos más interesantes, sobre todo en lo referente a textos sobre cultura y globalización, especialista precisamente en eso que él ha denominado mediaciones tecnológicas (2005). Gustavo Guerrero, al comentar la obra del pensador colombiano, señala «su costumbre de publicar sus textos diseminándolos en los soportes y formatos más variados», dentro de una concepción del ensayo como «obra abierta» (2014: 16), que le permite remediar y reformular sus textos de unos sitios a otros, de libros a blogs, de artículos y vídeos a conferencias, etcétera. Es decir, Martín-Barbero ha creado un dispositivo ensayístico, desde el que genera pensamiento móvil, renovado, actualizado y accesible desde cualquier punto de acceso a lo digital, entendiendo con agudeza la mediación tecnológica desde dentro.

El escritor e investigador Eduardo Navas ha configurado su web personal como un conjunto interrelacionado de ensayos, que a veces son reescrituras de otros, conservando la escritura original. Por ejemplo, y no poco significativamente, hace dos trabajos analítico-estadísticos, en dos épocas distintas, sobre el Minima moralia de Adorno. Su libro Spate: A Navigational Theory of Networks (2016) está construido a partir de la remediación y reescritura parcial de los tuits de su cuenta de Twitter @ poemita publicados entre 2010 y 2014, estableciendo una reflexión desde diversos puntos de vista enunciativos acerca de la circulación de la información y de la teoría en nuestros tiempos, de forma que Spate es, en realidad, una especie de metaensayo digital, sin el 
que las tecnologías compresivas de comunicación, como reconoce el propio autor: «the content in Spate could not have been written without the compression of information at play across networks at the time of this writing. Twitter is unique in this sense» (Navas 2016: 76). Spate es, por tanto, ensayo + Twitter, o red social devenida ensayo, como prefiramos entenderlo, y es una vía de ahondar en el género ensayístico aprovechando las posibilidades de los nuevos medios.

Por su parte, El brasileño André Vallias aborda otra posibilidad experimental de repensamiento de lenguajes en TraklTakt (2003), «un collage intermediático y multigenérico entre poesía, narrativa y ensayo filosófico; un poema digital que remediatiza (...) múltiples fragmentos preexistentes (diarios, poemas, ensayos críticos) que están interrelacionados» (Ledesma 2015), algo hasta cierto punto natural, puesto que la intergenericidad y la remediación (Bolter y Grusin, 1996: 313) son dos constantes de la literatura de nuestro tiempo, no sólo de la digital. Otro modelo de trabajo, donde además se intentaba deliberadamente ampliar las posibilidades del hipertexto para la crítica, es el hiperensayo de Andrés Zamora «Un ensayo hipertextual. Propuesta para una ilustración apócrifa de La Regenta» (2006), con un exhaustivo empleo de enlaces a imágenes y recursos digitales.

\section{Conclusiones}

Es cierto que la red ha alterado algunas estructuras tradicionales de recepción, rompiendo los marcos de recepción tradicionales del arte y la literatura (Groys 2016: 195), de forma que no es fácil saber lo que merece la pena y lo que no, lo cual afecta también al mundo del ensayo. Pero no debemos olvidar que también las colecciones tradicionales de ensayo se poblaban de ensayos mediocres, de malos ensayos y de ensayos-basura. Favores editoriales, nepotismo, encargos, editores dedicados a la autoedición de sí mismos, han saturado durante siglos las librerías y bibliotecas de ensayos absurdos e innecesarios. No es el soporte, sino el talento, lo que hace que un ensayo sea excelente. Tampoco su forma es relevante; no faltará quien diga que la fragmentaria Minima moralia de Adorno es tan o más imprescindible que otros ensayos suyos más tradicionales. Es el talento, de nuevo, lo que consigue que un contenido y una forma encajen como un solo ser en una creación ensayística meritoria y de lectura deseable, gracias a un particular modo de «funcionamiento» (Besa Camprubí, 2014: 120) que es la almendra conceptual de lo ensayístico. 
En ese marco, el ensayo digital, como hemos intentado demostrar en este hiperensayo, es sólo una más de las evoluciones históricas que este género proteico nos ofrece, precisamente porque la adaptación, la supervivencia y la flexibilidad viajera son algunas de sus características: «el ensayo se acomoda. Se expande. Se contrae. Es una tecnología flexible» (Monson, 2011), es una práctica de escritura y pensamiento «elástica y flotante» (Amara 2012), destinada a flotar eternamente en el ciberespacio de la inteligencia humana, mientras ésta perdure.

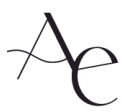

\section{Bibliografía}

Ara Torralba, Juan Carlos: «De Ayala a Baroja: Mainer o la renovación de la historiografía literaria española contemporánea. Una bibliografía (1965-2012)», Anales de la Literatura Española Contemporánea, 38, 1-2 (2013), pp. 7-44.

AarSETH, Espen: Cibertext. Perspectives on Ergodic Literature. Baltimore: Johns Hopkins University Press, 1997.

AmARA, Luigi: «El ensayo ensayo», Letras Libres, 05/02/2012, http://www.letraslibres.com/mexico/ el-ensayo-ensayo\# ftnref2.

Aullón de Haro, Pedro: Teoría del ensayo. Madrid: Verbum, 1992.

Abenshushan, Vivian: «Prólogo. Contraensayo», en Álvaro Uribe (coor.), Contraensayo. Antología de ensayo mexicano actual. Selección de V. Abenshushan. México D.F.: UNAM, 2012, pp. 7-17.

Aвuín, Anxo: "All the web is a stage: twittoperas o Shakespeare más abreviado que nunca», Pasavento. Revista de Estudios Hispánicos, I, 2 (verano 2013), pp. 231-246.

Adorno, Th. W.: Notas de literatura. Obra completa, 11. Madrid: Akal, 2003.

Beck, Ulrich: Risk Society: Towards a New Modernity. Londres: Sage, 1992.

Besa Camprubí, Carles: «El ensayo en la teoría de los géneros», Castilla. Estudios de Literatura, 5 (2014): pp. 101-123.

BlanChOt, Maurice: El espacio literario. Barcelona: Paidós, 1992. 
Bolter, Jay David, y Grusin, Richard: «Remediation», Configurations 4, 3 (1996), pp. 311-358.

Broncano, Fernando: La estrategia del simbionte. Salamanca: Delirio, 2012.

$\mathrm{BuJ}$, Joseba, «EXERGO (que delira hacia una nueva cognición, hacia una nueva subjetividad, hacia una nueva condición política: la narrativa digital como abigarrado lugar para el ejercicio crítico)», en Johanna Ángel Reyes, Joseba Buj e Ivonne Lonna (coors.), Im/ pre-visto. Narrativas digitales. México D.F.: Fundación Telefónica / Paidós, 2016, pp. 149-177.

Caballé, Anna: «¿Cansados del yo?», Babelia, El País 07/01/2017, accesible en http://cultura. elpais.com/cultura/2017/01/06/babelia/1483708694_145058.html.

CAStells, Manuel: La era de la información. Volumen 1: La sociedad red. Madrid: Alianza, 2000.

Cruz Arzabal, Roberto: «Dispositivos artísticos postdigitales: escrituras de ida y vuelta». Red de Humanidades digitales, 2014. En http://humanidadesdigitales.net/blog/2014/04/18/ dispositivo s-artisticos-post-digitales-escrituras-de-ida-y-vuelta/.

Deleuze, Gilles: «Qué es un dispositivo», en AA.VV., Michel Foucault filósofo. Barcelona: Gedisa, 1990.

Doce, Jordi: Perros en la playa. Madrid: La Oficina, 2011.

Escandell MontieL, Daniel: «El libro en la pantalla: hacia un nuevo ensayo en el siglo XXI con la escritura y edición digital», Humanidades Digitales: una aproximación transdisciplinar. Janus, Anexo 2 (2014), pp. 73-83.

Esposıto, Scott y Jacques, Juliet: «Un espejo o una ventana», Granta, 18, nueva época 5, 2016, pp. 111-120.

Fernández MASSARA, María Belén: «Sobre libros y pantallas: encuentros y desencuentros en la Cultura Digital», Estudios sobre las Culturas Contemporáneas, XX, 40 (2014), pp. 117140.

García, Eduardo: Las islas sumergidas. Granada: Cuadernos del Vigía, 2014.

Gatica Cote, Paulo A.: «El galope veloz de los centauros: aforismo y ensayo en los tiempos del Twitter», en Reindert Dhont y Dagmar Vandebosch (eds), Transnacionalidad e hibridez en el ensayo hispánico: un género sin orillas, Leyden / Boston: Brill, 2016, pp. 256-271.

Gavilán Muñoz, Alberto: «El ensayo como desplazamiento», Analecta. Revista de Humanidades, 4 (Primer Semestre 2010), pp. 73-82. 
Giordano, Alberto: «Prólogo. El discurso sobre el ensayo» a Alberto Giordano (ed.), El discurso sobre el ensayo en la cultura argentina desde los 80, Buenos Aires: Santiago Arcos, 2015, pp. 5-29.

GoETHE, Johann Wolfgang: «El ensayo como mediador entre objeto y sujeto», Analecta malacitana, Anejo XXIX: Goethe, Ensayos sobre arte y literatura, Universidad de Málaga, 2000.

Grors, Boris: Arte en flujo. Ensayos sobre la evanescencia del presente. Buenos Aires: Caja Negra, 2016.

GuerRero, Gustavo: «Modos, rutas y derivas del ensayo contemporáneo. De la tierra firme al mar sin orillas», Revista de la Universidad de México, 126 (agosto) 2014, pp. 63-75.

-«Jesús Martín-Barbero. Tiempo y espacio, nación y globalización en América Latina entre dos siglos», en Erica Durante (ed.), Los meridianos de la globalización. Ensayos sobre el tiempo en la literatura latinoamericana contemporánea, UCL Presses Universitiares de Louvain, Louvain-La-Neuve, 2015, pp. 15-26.

Holmes, Brian, 2007. «El dispositivo artístico, o la articulación de enunciaciones colectivas», Marcelo Expósito, trad. Brumaria, 7 (Arte, máquinas, trabajo inmaterial), pp. 144-167. http://marceloexposito.net/pdf/trad holmes dispositivoartistico.pdf.

Itlouz, Eva: Intimidades congeladas. Las emociones en el capitalismo. Buenos Aires: Katz, 2007. JACOBS, Bárbara: «El ensayo literario», ABCD las Artes y las Letras, 01/03/2008, p. 27.

JARAUTA, Francisco: «Reflexiones transversales sobre filosofía y literatura (seguido de 10 tesis)»; en AA.VV., Literatura y filosofía en la crisis de los géneros, Madrid: Fundación Juan March, 1999, pp. 49-63.

JAROSINSKI, Eric: Nein. Un manifiesto. Barcelona: Anagrama, 2016.

JIMÉNEZ, José: La vida como azar. Barcelona: Mondadori, 1989.

LeDESMA, Eduardo: «André Vallias y el tema de la traducción», en Luis Correa-Díaz y Scott Weintraub (eds.), Poesía y poéticas digitales - electrónicas - tecnos - new-media en América Latina: definiciones y exploraciones. Bogotá: Ediciones Universidad Central, 2015 (libro electrónico).

López PozA, Sagrario: «Humanidades Digitales hispánicas», en Rocío Barros Roel (ed.), Cincuentenario de la Asociación Internacional de Hispanistas, A Coruña, 11-13 diciembre de 2012. A Coruña: Servizo de Publicacións Universidade da A Coruña, 2014, pp. 151-160. 
LuKÁcs, Georg: El alma y las formas. México D. F.: Grijalbo, 1985.

MAINER, José Carlos: Libros, tramas, nombres. Barcelona: Anagrama, 2005.

Martín-Barbero, Jesús: América Latina: otras visiones de la cultura. Bogotá: Convenio Andrés Bello, 2005.

Monson, Ander: «El ensayo como hackeo», Hermano Cerdo, julio 2011, http://hermanocerdo. com/2011/07/el-ensayo-como-hackeo/.

Mora, Vicente Luis: Pangea. Internet, blogs y comunicación en un mundo nuevo. Sevilla: Fundación J. M. Lara, 2006.

--------«Redes sociales, textovisualidad y transmedia: literatura y nuevas tecnologías», El Español en el mundo. Anuario del Instituto Cervantes 2012, Instituto Cervantes/Agencia Estatal del Boletín O. del Estado, Madrid, 2012, accesible en http://cvc.cervantes.es/lengua/ anuario/anuario 12/luis/p04.htm.

- «Text and Internext: The Literary Change to fluid Texts and its Effect in current Narrative», The Publishing Lab, 2013, http://the-publishing-lab.com.

----------«Fragmentarismo y fragmentalismo en la narrativa hispánica», Cuadernos hispanoamericanos, № 783 (2015), pp. 91-103.

----------«Formas y deformaciones: el nanorrelato vía Internet», en Eva Álvarez Ramos y María Martínez Deyros (eds.), Historias mínimas. Estudios teóricos y aplicaciones didácticas del microrrelato. Valladolid: Cátedra Miguel Delibes, 2016, pp. 95-124.

Musı, Robert: El hombre sin atributos, 1. Traducción de José M. Saénz. Barcelona: Seix Barral, 2002.

Navas, Eduardo: Spate: A Navigational Theory of Networks. Amsterdam: Institute of Network Cultures, 2016.

Pons, Anaclet: El desorden digital. Guía para historiadores y humanistas. Madrid: Siglo XXI, 2013. Pozuelo Yvancos, José María: «El género literario ensayo», en Vicente Cervera, Belén Hernández y $\mathrm{M}^{a}$ Dolores Adsuar (eds.), El ensayo como género literario, Murcia: Universidad de Murcia, Servicio de Publicaciones, 2005, pp. 179-191.

RYan, Marie-Laure: «Hacia una teoría de la competencia genérica», en Miguel Ángel Garrido Gallardo (coor.), Teoría de los géneros literarios, Madrid: Arco Libros, 1988, pp. 253-302. 
Scoları, Carlos S.: Ecología de los medios. Entornos, evoluciones e interpretaciones. Barcelona: Gedisa, 2015.

Serna Arango, Julián: «Borges y la escritura fragmentada», en Félix Duque, Julián Serna Arango y Rubén Serra Mejía (eds.), Paradojas en línea. En torno a Borges y Cervantes, Siglo del Hombre Editores, Universidad Tecnológica de Pereira y Pontificia Universidad Javierana-Instituto Pensar, Bogotá, 2006, pp. 49-82.

Souto, Arturo: El ensayo. Complejo Editorial Latinoamericano, México D.F., 1973.

SPENCE, Paul: «Prólogo: La investigación en Humanidades Digitales en el mundo hispano», en Esteban Romero Frías y María Sánchez González (eds.), Ciencias Sociales y Humanidades Digitales: técnicas, herramientas y experiencias de e-Research e investigación en colaboración, La Laguna: Sociedad Latina de Comunicación Social, 2014, pp. 9-12.

STAROBINSKY, Jean: «¿Es posible definir el ensayo?», Cuadernos Hispanoamericanos, 575 (mayo 1998), pp. 31-40.

TURKLE, Sherry: La vida en la pantalla. Barcelona: Paidós, 1997.

VAlente, José Ángel: Anatomía de la palabra. Valencia: Pre-Textos, 2000.

ZAMORA, Andrés: «Un ensayo hipertextual. Propuesta para una ilustración apócrifa de La Regenta», Revista Canadiense de Estudios Hispánicos, 31, 1 (2006): pp. 175-197. 